\title{
Dynamic Study of Farmers' Information Adoption in China
}

\author{
Jingjing Zhang ${ }^{1}$, Lu Liu ${ }^{1}$, Jian Zhang ${ }^{2}$, and Jinyou $\mathrm{Hu}^{1, *}$ \\ ${ }^{1}$ College of Engineering, China Agricultural University, Beijing, 100083, P.R. China \\ ${ }^{2}$ Beijing Information Science \& Technology University, Beijing, 100192, P.R. China \\ zhangjingjing1982@126.com
}

\begin{abstract}
Agriculture information has played an important part in recently years. The adoption of agriculture information is a dynamic process and many factors have influences on farmers' information usage motivation and willingness. The main objective of this paper is to analyze and predict the variations of farmers' decisions in order to make the information more reachable to farmers. In this study, farmers are divided into three categories based on the style of risk preference, which are the risk evaders, risk likers and risk neutrals. To compare the difference of the information adoption rates across varied sections of farmers, we extend our research and the factor of time is added into the model. A sample of 34 farmers takes part in the continuous surveys with the duration of one year. By the simulation and analysis in the light of the information usage intention equation, it is found that farmers' information demand presents a characteristic of seasonality and keeps stable after a period.
\end{abstract}

Keywords: Information Demand, Adoption, Risk Preference, Dynamic Behavior.

\section{Introduction}

Agriculture information has presented a significant role. At present, farmers are supplied with a considerable variety of agriculture information in China. However, the proportion of the information that farmers can make full use of is small, which is mainly due to the distance between information supply and acceptance.

In the past years, the agriculture information acceptance has been given special attention in academic studies in China. Many studies were concerned about the variety of information which farmers cared about mostly and the efficient ways of transferring agricultural information. Few researches were carried out from the point of farmers' dynamic behavior. Researchers and practitioners have long been of great interest to the process in which consumers make their purchase decisions (Tao Zhang al., 2007). Researches into farmers' information decision-making increase the understanding of the dynamic behavior. Therefore, it is significant to explain and predict

\footnotetext{
${ }^{*}$ Corresponding author.
} 
farmers' information adoption decision. This article aims to enhance our current understanding about farmers' decision-making as time goes by.

\section{Methodology}

In the previous studies, a skeleton questionnaire was designed to guide the structured interviews with information usage intention, the purpose of which was to collect more in-depth knowledge about the farmers' difficulties and reflection for adopting agriculture information. It was more likely to provide the factors which have impact on their decisions. The items in the questionnaires were measured on a 5-point Likert-type scale ( $1=$ strongly disagree to $5=$ strongly agree). Data in the study were collected with a sample of two hundred and thirty-one farmers from thirteen different areas in China.

Farmers' agriculture information acceptance regression function was gained by the binary logistic regression. The determinants of farmers' agriculture information acceptance were derived, which were experience, searching motivation, perceived usefulness, risk preference and income. Results are shown as Figure 1.

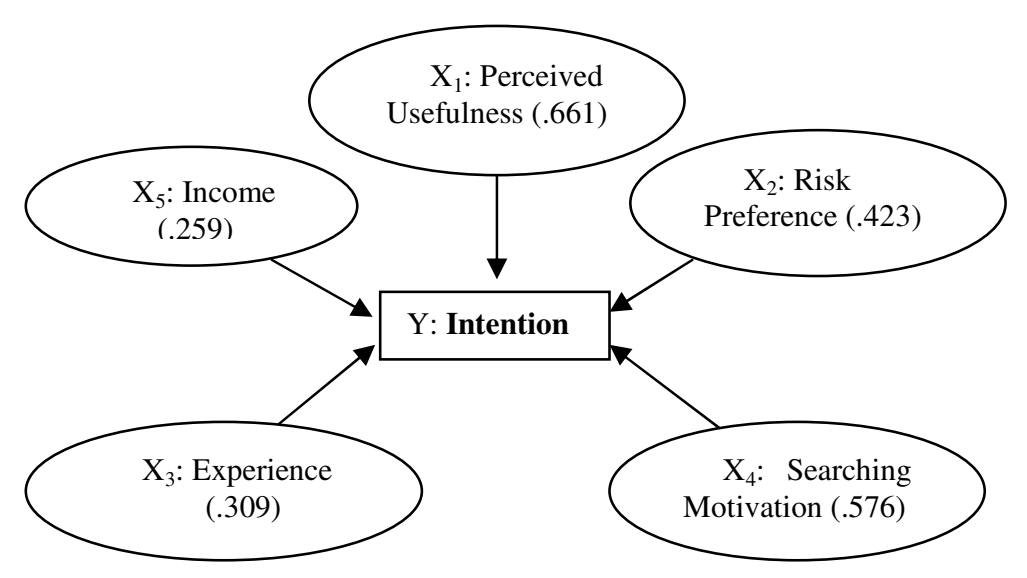

Fig. 1. The information usage intention model

The logistic regression equation is as (1), and the information usage intention equation is as (2). Here, Y means the possibility that the intention is positive.

$$
\begin{aligned}
g_{1}=\operatorname{Logit}\left[\frac{P(\text { yes })}{P(\text { no })}\right] & =-3.102+0.259 x_{5}+0.309 x_{3} \\
& +0.423 x_{2}+0.576 x_{4}+0.661 x_{1}
\end{aligned}
$$




$$
Y(y e s)=\frac{e_{g_{1}}}{1+e_{g_{1}}}
$$

\section{Survey}

There have been a large number of studies that examined the interplay between personality and information processing (Edwards, 2003). Decisions are influenced by the subjective consciousness. Consumers may have the different decisions towards the same product based on the characteristics.

Farmers' information behavior is a changing process. But it will take a long time to observe the behavior of farmers. Having obtained the logistic regression model of farmers' information usage intention, the study has selected a small sample of 34 people who are in the same condition as the sample of the first round, as is shown in table1.

Table 1. Characteristics of the sample

\begin{tabular}{cll}
\hline \multicolumn{1}{c}{ Categories } & Number & Percentage \% \\
\hline Gender & 24 & 70.6 \\
Male & 10 & 29.4 \\
Female & & \\
Age group & 7 & 20.6 \\
From 18-30 & 11 & 32.4 \\
From 31-40 & 10 & 29.4 \\
From 41-50 & 5 & 14.7 \\
From 51-60 & 1 & 2.9 \\
Over 60 & & \\
Education level & 3 & 8.8 \\
None & 9 & 26.5 \\
Primary education & 15 & 44.1 \\
Secondary education & 6 & 17.6 \\
Higher education & 1 & 2.9 \\
Over &
\end{tabular}

In this study, farmers are divided into three categories based on the style of risk preference, which are the risk evaders, risk neutrals and risk likers. The ratio of three types is about 1:11:5. Five surveys at the same intervals have been carried out for one year in this study.

\section{Analysis}

The analysis presents that there is no significant difference and characteristics of the need among different types of information. Basically, the usage intention for the five type information is intensively, as is shown in figure 2. 
Farmers' intention of different types of information does not show a prominent feature from the point of time. In the word, at the beginning and the end of the year, the demand for the information keeps high, as is shown in figure 3. The information usage intention of the farmers who are risk likers keeps stable, however, the risk evaders' information usage intention fluctuates largely and farmers are more interested in the information which is easy to understand, for example, the information of agricultural product price and wealth experience.

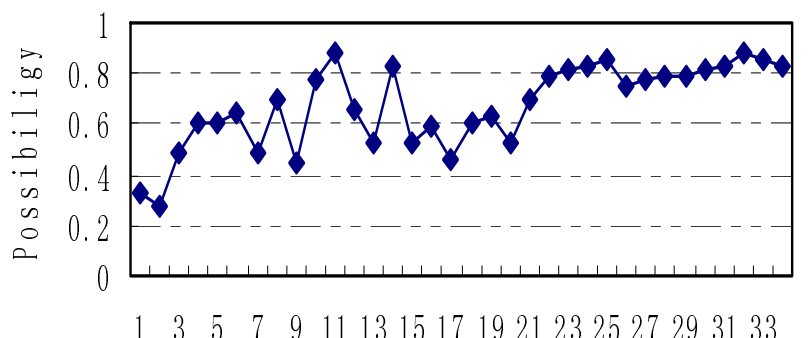

Number

Fig. 2.1. The agriculture technology information

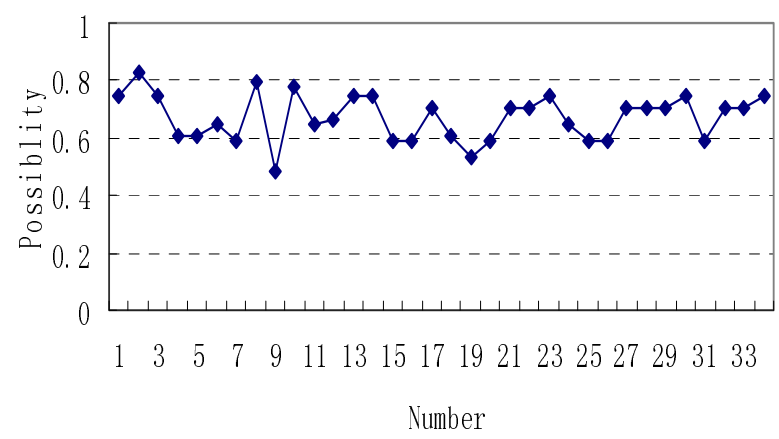

Fig. 2.2. The wealth experience

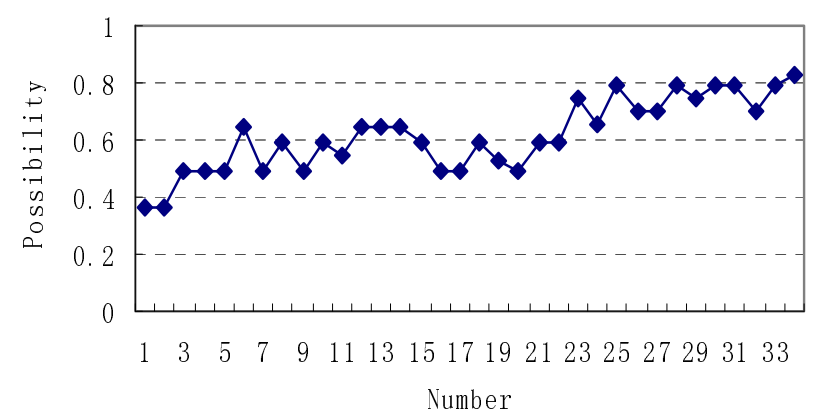

Fig. 2.3. The brand information

Fig. 2. The variety of usage intention for different types of information 


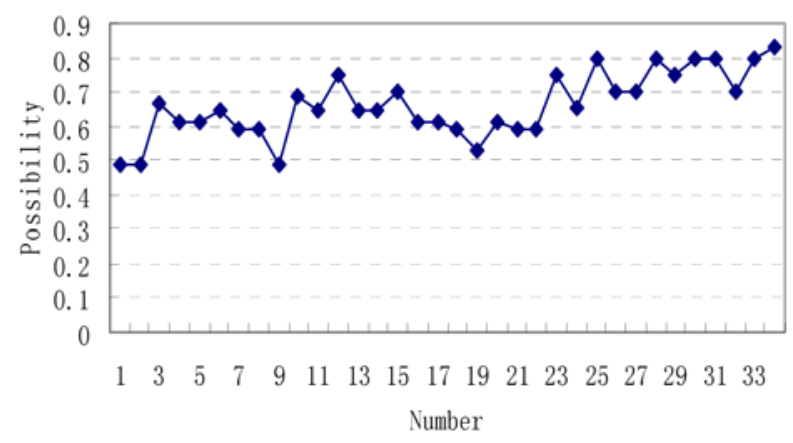

Fig. 2.4. The market analysis report

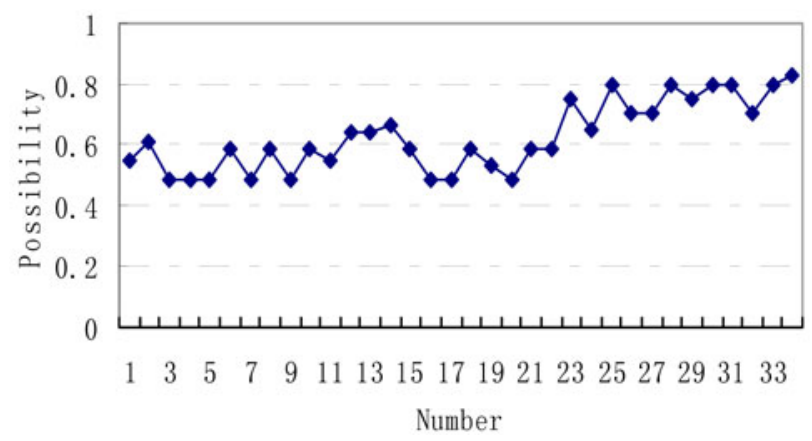

Fig. 2.5. The agricultural product price

Fig. 2. (continued)

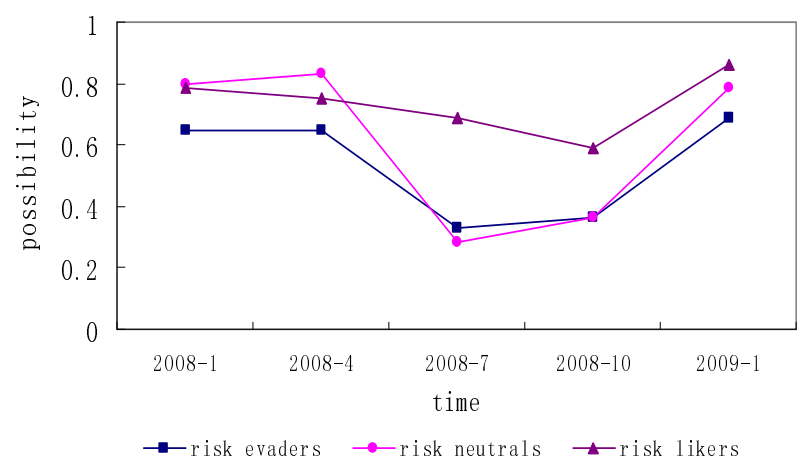

Fig. 3. The variety of the usage intention of three types of farmers

In order to analyze the process of farmers' information adoption behavior exactly, the paper adjusts the sample of 34 farmers according to the personal characteristics. The initiation time and 12 farmers are selected to analyze in detail. 
The time point of January 2008 is taken as the base point and a week (7 days) is regarded as the time interval. The original data are transformed to the data of a farmer in 60 time points. After compilation of the 60 sets data, the paper analyses the changing process of the farmers' information usage intention, as is shown in figure 4.

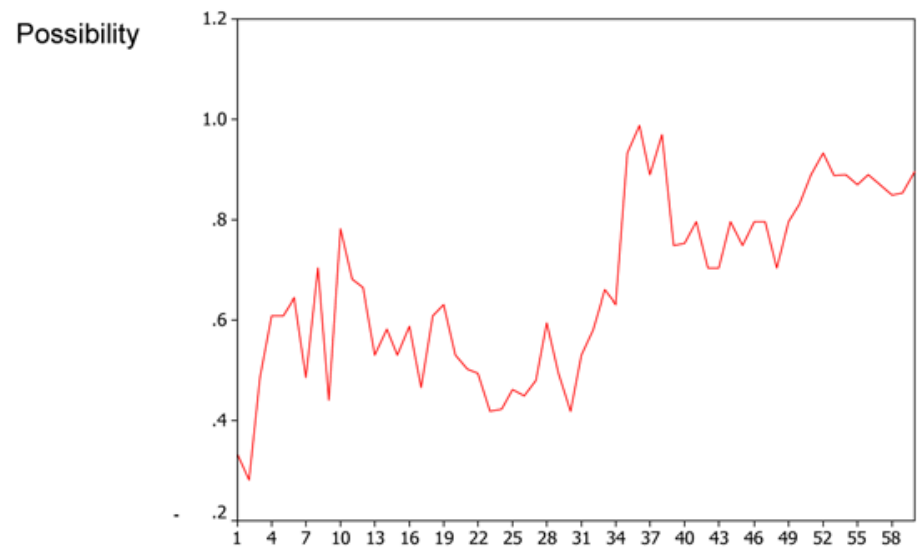

Time

Fig. 4. The variety of the usage intention of the individual

As is presented in the time angle, the intention for the information is highest during the period from December to February of next year and lowest from July to September. It can be explained from the point of farmers' geographical environment and the crop's growth cycle. The information usage intention almost tends to be stable after 49 weeks. It may be concluded that farmers' confidence for the information product and the service will increase after a period and the demand will not fluctuate violently.

\section{Conclusion}

In this paper, a small scale sample is selected and continuous surveys are carried out to exam farmers' information usage intention variation in China. It is found that farmers' information behavior is a dynamic process and has presented seasonal characteristics. The findings also highlight that farmers' confidence on the information product and the information service may be stable after a period of time.

The results might not be rather correct because of the small sample. In the future study, it could be focused on the variation of the determinants based on a larger sample in order to investigate farmers' agriculture information decision-making deeply.

\section{References}

1. Davis, F.D.: Perceived Usefulness, Perceived Ease of Use, and User Acceptance of Information Technology. IS Quarterly, 319-340 (1989)

2. Lee, H.-H., Fiore, A.M., Kim, J.: The Role of the Technology Acceptance Model in Explaining Effects of Image Interactivity Technology on Consumer Responses. International Journal of Retail \& Distribution Management 8, 621-644 (2006) 
3. Edwards, J.A.: The Interactive Effects of Processing Preference and Motivation on Information Processing: Causal Uncertainty and the MBTI in a Persuasion Context. Journal of Research in Personality 37, 89-99 (2003)

4. Horst, M., Kuttschreuter, M., Gutteling, J.M.: Perceived Usefulness, Personal Experinces, Risk Perception and Trust as Determinants of Adoption of E-government Services in The Netherlands. Computers in Human Behavior 23, 1838-1852 (2007)

5. Lynch, N., Berry, D.: Differences in Perceived Risks nd Benefits of Herbal, over-thecounter Conventional, and Prescribed Conventional, Medicines, and the Implications of this for the Safe and Effective Use of Herbal Products. Complementary Therapies in Medicine 15, 84-91 (2007)

6. McKechnie, S., Winklhofer, H., Ennew, C.: Applying the Technology Acceptance Model to the Online Retailing of Financial Services. International Journal of Retail \& Distribution Management 34, 388-410 (2006)

7. Zhang, T., Zhang, D.: Agent-based Simulation of Consumer Purchase Decision-making and the Decoy Effect. Journal of Business Research 60, 912-922 (2007)

8. King, W.R., He, J.: A Meta-analysis of the Technology Acceptance Model. Information \& Management 43, 740-755 (2006)

9. Wang, Y.-S., Wang, H.-Y., Shee, D.Y.: Measuring E-learning Systems Success in an Organizational Context: Scale Development and Validation. Computers in Human Behavior 23, 1792-1808 (2007) 